Employee of: Novartis Pharma GmbH, Hans-Peter Tony Consultant of: AbbVie, Astra-Zeneca, BMS, Chugai, Janssen, Lilly, MSD, Novartis, Pfizer, Roche, Sanofi DOI: 10.1136/annrheumdis-2021-eular.141

\section{POS0900 SECUKINUMAB 150 MG PROVIDES SUSTAINED IMPROVEMENT IN SIGNS AND SYMPTOMS OF NON-RADIOGRAPHIC AXIAL SPONDYLOARTHRITIS: 2-YEAR RESULTS FROM THE PREVENT STUDY}

D. Poddubnyy ${ }^{1}$, A. Deodhar ${ }^{2}$, X. Baraliakos ${ }^{3}$, R. Blanco ${ }^{4}$, E. Dokoupilova ${ }^{5}$, S. Hall ${ }^{6}$, A. Kivitz ${ }^{7}$, M. G. H. Van de Sande ${ }^{8}$, A. Stefanska ${ }^{9}$, P. Pertel ${ }^{10}$, H. Richards ${ }^{10}$, J. Braun ${ }^{11} .{ }^{1}$ Charité - Universitätsmedizin Berlin, German Rheumatism Research Centre, Berlin, Germany; ${ }^{2}$ Oregon Health \& Science University, Division of Arthritis and Rheumatic Diseases, Portland, United States of America; ${ }^{3}$ Rheumazentrum Ruhrgebiet, Rheumatology Division, Herne, Germany; ${ }^{4}$ Hospital University Marqués de Valdecilla, IDIVAL, Division of Rheumatology, Santander, Spain; ${ }^{5}$ Medical Plus, s.r.o., Uherske Hradiste, Masaryk University, Department of Pharmaceutical Technology, Faculty of Pharmacy, Brno, Czech Republic; ${ }^{6}$ Monash University, Department of Medicine, Melbourne, Australia; ${ }^{7}$ Altoona Center for Clinical Research, Clinical Research Division, Pennsylvania, United States of America; ${ }^{8}$ Amsterdam UMC, University of Amsterdam, Amsterdam Rheumatology and Immunology Center, Amsterdam, Netherlands; ${ }^{9}$ Novartis Ireland Limited, Immunology, Hepatology and Dermatology, Dublin, Ireland; ${ }^{10}$ Novartis Pharma AG, Immunology, Hepatology and Dermatology, Basel, Switzerland; ${ }^{11}$ Rheumazentrum Ruhrgebiet, Herne, and Ruhr-University Bochum, Department of Rheumatology, Bochum, Germany

Background: Axial spondyloarthritis (axSpA) is an inflammatory disease characterised by chronic back pain, and it comprises radiographic axSpA and non-radiographic axSpA (nr-axSpA). ${ }^{1}$ Secukinumab (SEC) $150 \mathrm{mg}$, with (LD) or without loading (NL), dose significantly improved the signs and symptoms of patients with nr-axSpA in the PREVENT (NCT02696031) study through Week $52 .{ }^{2}$

Objectives: To report the long-term clinical efficacy and safety of secukinumab from the PREVENT study through 2 years.

Methods: A detailed study design, key primary and secondary endpoints have been reported previously. ${ }^{2}$ In total, 555 patients fulfilling ASAS criteria for axSpA plus abnormal C-reactive protein (CRP) and/or MRI, without evidence of radiographic changes in sacroiliac (SI) joints according to modified New York Criteria for AS were randomised (1:1:1) to receive SEC $150 \mathrm{mg}$ with $\mathrm{LD}$, NL, or placebo (PBO) at baseline. LD patients received SEC $150 \mathrm{mg}$ at Weeks 1, 2, 3, and 4, and then every 4 weeks (q4wk) starting at Week 4 . NL patients received SEC $150 \mathrm{mg}$ at baseline and PBO at weeks 1, 2, and 3, and then $150 \mathrm{mg} \mathrm{q} 4 \mathrm{wk} .90 \%$ patients were anti-tumour necrosis factor (anti-TNF) naïve, 57\% had elevated CRP and $73 \%$ had evidence of SI joint inflammation on MRI. All images were assessed centrally before inclusion. All patients continued to receive open-label SEC $150 \mathrm{mg}$ treatment after Week 52. Efficacy assessments through Week 104 included ASAS40 in anti-TNFnaïve patients, ASAS40, BASDAI change from baseline, BASDAI50, ASAS partial remission, and ASDAS-CRP inactive disease in the overall population. The safety analyses included all patients who received $\geq 1$ dose of study treatment for the entire treatment period up to Week 104. Data are presented as observed.

Results: Overall, 438 patients completed 104 weeks of study: 78.9\% (146/185; LD), $77.7 \%$ (143/184; NL) and 80.1\% (149/186; PBO). Efficacy results at Week 52 were sustained through Week 104 and are reported in the Table 1. The safety profile was consistent with the previous reports with no deaths reported during the entire treatment period up to Week $104 .^{2}$

Conclusion: Secukinumab $150 \mathrm{mg}$ demonstrated sustained improvement in the signs and symptoms of patients with nr-axSpA through 2 years. Secukinumab was well tolerated with no new or unexpected safety signals. REFERENCES:

[1] Strand V, et al. J Clin Rheumatol. 2017; 23(7):383-91.

[2] Deodhar A, et al. Arthritis Rheumatol. 2020. Online ahead of print.

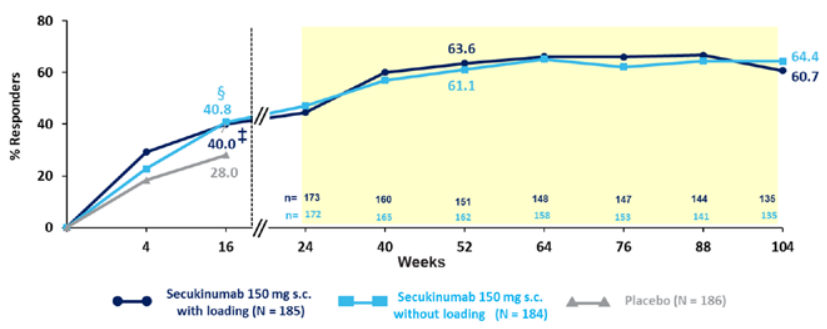

$\S \mathrm{p}<0.01$ and $\ddagger \mathrm{p}<0.05 \mathrm{vs}$ placebo (unadjusted p-values at Week 16). Data presented as non-responder imputation till week 16 an as observed from Week 24 to Week 104.At Week 52 all patients remaining on blinded treatment switched to open-label secukinumab.
ASAS, Assessment of SpondyloArthritis Intermational Society; $N$, total number of patients randomised; $n$, number of evaluable patients including those who switched to open label secukinumab or standard of care after Week 20 . After Week 52 , only patients who

Figure 1. ASAS40 response was maintained through Week 104 in the overall population
Table 1. Summary of clinical efficacy (Observed data)

\begin{tabular}{|c|c|c|c|c|}
\hline Endpoints & Week & $\begin{array}{c}\text { SEC } 150 \mathrm{mg} \\
\text { LD } \\
(\mathrm{N}=185)\end{array}$ & $\begin{array}{l}\text { SEC } 150 \mathrm{mg} \mathrm{NL} \\
(\mathrm{N}=184)\end{array}$ & $\begin{array}{c}\text { PBO-SEC } \\
-\quad 150 \mathrm{mg} \\
(\mathrm{N}=186)\end{array}$ \\
\hline $\begin{array}{l}\text { *ASAS40 in anti-TNF-naïve } \\
\text { patients, } n / M(\%)\end{array}$ & $\begin{array}{l}52^{\mathrm{a}} \\
104\end{array}$ & $\begin{array}{l}90 / 137(65.7) \\
78 / 123(63.4)\end{array}$ & $\begin{array}{l}95 / 145(65.5) \\
83 / 123(67.5)\end{array}$ & $\begin{array}{l}85 / 151(56.3) \\
83 / 134(61.9)\end{array}$ \\
\hline $\begin{array}{l}\text { BASDAI change from baseline, } \\
\text { mean } \pm \text { SD }\end{array}$ & $\begin{array}{l}52^{\mathrm{a}} \\
104\end{array}$ & $\begin{array}{l}-3.7 \pm 2.8 \\
-4.1 \pm 2.6\end{array}$ & $\begin{array}{l}-3.7 \pm 2.6 \\
-3.9 \pm 2.6\end{array}$ & $\begin{array}{l}-3.3 \pm 2.4 \\
-3.7 \pm 2.5\end{array}$ \\
\hline BASDAI50, n/M (\%) & $\begin{array}{l}52^{\mathrm{a}} \\
104\end{array}$ & $\begin{array}{l}90 / 153(58.8) \\
88 / 137(64.2)\end{array}$ & $\begin{array}{l}92 / 163(56.4) \\
84 / 136(61.8)\end{array}$ & $\begin{array}{l}90 / 161(55.9) \\
87 / 142(61.3)\end{array}$ \\
\hline ASAS partial remission, & $\begin{array}{l}52^{\mathrm{a}} \\
104\end{array}$ & $\begin{array}{l}46 / 152(30.3) \\
51 / 137(37.2)\end{array}$ & $\begin{array}{l}56 / 163(34.4) \\
50 / 135(37.0)\end{array}$ & $\begin{array}{l}46 / 161(28.6) \\
50 / 142(35.2)\end{array}$ \\
\hline n/M (\%) & & & & \\
\hline $\begin{array}{l}\text { ASDAS CRP inactive disease, } \\
\mathrm{n} / \mathrm{M}(\%)\end{array}$ & $\begin{array}{l}52^{\mathrm{a}} \\
104\end{array}$ & $\begin{array}{l}49 / 152(32.2) \\
50 / 132(37.9)\end{array}$ & $\begin{array}{l}58 / 163(35.6) \\
53 / 133(39.8)\end{array}$ & $\begin{array}{l}48 / 160(30.0) \\
53 / 142(37.3)\end{array}$ \\
\hline
\end{tabular}

${ }^{*}$ For anti-TNF-naïve patients, N=164, LD; 166, NL; 171, PBO-SEC. ${ }^{a}$ total number of evaluable patients including open-label SEC and standard of care (SOC; 2 patients in LD, 1 patient in $\mathrm{NL}$ continued on SOC). After Week 52, only patients who continued to receive open-labe SEC are presented.ASAS, Assessment of SpondyloArthritis International Society; ASDAS, Ankylosing Spondylitis Disease Activity Score; BASDAI, Bath Ankylosing Spondylitis Disease Activity Index; $\mathrm{M}$, number of patients with evaluation; $\mathrm{N}$, total randomised patients; $n$, number of patients who are responders; SD, standard deviation

Disclosure of Interests: Denis Poddubnyy Speakers bureau: AbbVie, BMS, Eli Lilly, MSD, Novartis, Pfizer, UCB, Consultant of: AbbVie, Biocad, BMS, Eli Lilly, Gilead, MSD, Novartis, Pfizer, Samsung Bioepis, UCB, Grant/research suppor from: AbbVie, MSD, Novartis, Pfizer, Atul Deodhar Speakers bureau: AbbVie Amgen, Boehringer Ingelheim, Bristol Myer Squibb (BMS), Eli Lilly, GSK, Janssen, Novartis, Pfizer, and UCB, Consultant of: AbbVie, Amgen, Boehringer Ingelheim, Bristol-Myers Squibb, Celgene, Eli Lilly, Gilead, GSK, Janssen, Novartis Pfizer, and UCB, Grant/research support from: AbbVie, Eli Lilly, GSK, Novartis, Pfizer, and UCB, Xenofon Baraliakos Speakers bureau: AbbVie, BMS, Celgene, Chugai, MSD, Novartis, Pfizer, and UCB, Consultant of: AbbVie, BMS Celgene, Chugai, Galapagos, Gilead, MSD, Novartis, Pfizer, and UCB, Grant/ research support from: AbbVie and Novartis, Ricardo Blanco Speakers bureau AbbVie, Pfizer, Roche, Bristol-Myers, Janssen, UCB pharma and MSD and Eli Lilly, Consultant of: AbbVie, Pfizer, Roche, Bristol-Myers, Janssen, UCB pharma and MSD, Grant/research support from: AbbVie, MSD, and Roche, Eva Dokoupilova Grant/research support from: AbbVie, Affibody AB, Eli Lilly, Galapagos Gilead, GSK, Hexal AG, MSD, Novartis, Pfizer, R-Pharm, Sanofi-Aventis, and UCB, Stephen Hall Speakers bureau: Novartis, Merck, Janssen, Pfizer, Eli Lilly, and UCB, Consultant of: Novartis, Merck, Janssen, Pfizer, Eli Lilly, and UCB Grant/research support from: AbbVie, UCB, Janssen, and Merck, Alan Kivitz Shareholder of: Pfizer, Sanofi, Novartis, Amgen, GlaxoSmithKline, Gilead Sciences, Inc., Speakers bureau: Celgene, GlaxoSmithKline, Eli Lilly, Merck, Novartis, Pfizer, Sanofi, Genzyme, Flexion, AbbVie, UCB, Consultant of: AbbVie, Boehringer Ingelheim, Flexion, Janssen, Pfizer, Sanofi, Regeneron, SUN Pharma Advanced Research, Gilead Sciences, Inc., Marleen G.H. van de Sande Speakers bureau: Novartis, MSD, Consultant of: Abbvie, Novartis, Eli Lily, Grant/ research support from: Novartis, Eli Lilly, Janssen, UCB, Anna Stefanska Shareholder of: Novartis, Employee of: Novartis, Patricia Pertel Shareholder of: Novartis, Employee of: Novartis, Hanno Richards Shareholder of: Novartis, Employee of: Novartis, Juergen Braun Speakers bureau: Abbvie (Abbott), Amgen, BMS Boehringer, Celgene, Celltrion, Centocor, Chugai, EBEWE Pharma, Medac MSD (Schering-Plough), Mundipharma, Novartis, Pfizer (Wyeth), Roche, SanofiAventis and UCB pharma, Eli Lilly, Consultant of: Abbvie (Abbott), Amgen, BMS, Boehringer, Celgene, Celltrion, Centocor, Chugai, EBEWE Pharma, Medac MSD (Schering-Plough), Mundipharma, Novartis, Pfizer (Wyeth), Roche, SanofiAventis and UCB, Eli Lilly, Grant/research support from: Abbvie (Abbott), Amgen BMS, Boehringer, Celgene, Celltrion, Centocor, Chugai, Medac, MSD (Schering-Plough), Mundipharma, Novartis, Pfizer (Wyeth), Roche, Sanofi-Aventis and UCB, Eli Lilly

DOI: 10.1136/annrheumdis-2021-eular.143

\begin{tabular}{l|l}
\hline POS0901 & IXEKIZUMAB SHOWS A DISTINCT PATTERN OF \\
PAIN IMPROVEMENT BEYOND INFLAMMATION IN \\
RADIOGRAPHIC AXIAL SPONDYLOARTHRITIS
\end{tabular}

K. De Vlam ${ }^{1}$, G. Gallo², P. J. Mease ${ }^{3}$, P. Rahman ${ }^{4}$, V. Krishnan ${ }^{2}$, D. Sandoval ${ }^{2}$, C. Y. Lin ${ }^{2}$, R. Bolce ${ }^{2}$, P. G. Conaghan ${ }^{5} .{ }^{1}$ University Hospital Leuven, Rheumatology, Leuven, Belgium; ${ }^{2}$ Eli Lilly and Company, Lilly Corporate Centre, Indianapolis, United States of America; ${ }^{3}$ Swedish Medical Center/Providence St. Joseph Health and University of Washington, Rheumatology, Seattle, United States of America; ${ }^{4}$ Memorial University of Newfoundland, Medicine, St. John's, Canada; ${ }^{5}$ University of Leeds, School of Medicine, Leeds, United Kingdom

Background: The efficacy of ixekizumab (IXE) in biologic-naïve patients with radiographic axial spondyloarthritis ( $\mathrm{r}$-axSpA) has been previously presented using traditional axSpA outcome measures, such as BASDAI and ASAS. 
Objectives: In patients with active r-axSpA, to assess the analgesic efficacy of IXE as it relates to patient-reported and objective measures of inflammation. Methods: The Phase III COAST-V (NCT02696785) multi-center, randomized, double-blind, placebo (PBO)-controlled and active reference arm with adalimumab (ADA) trial investigated the efficacy of IXE in 341 patients (pts) with active r-axSpA for 52 weeks $(W)$. Pts were initially randomized to IXEQ4W, IXEQ2W, PBO, and ADAQ2W. At W16, pts assigned to PBO and ADA were re-randomized to IXEQ2W or Q4W Changes in spinal pain at night (SP-N) and spinal pain were measured at each study visit and analysed while controlling for CRP levels or mean of BASDAI questions 5 \& 6 (Q5: Duration and Q6: Intensity of morning stiffness). Observed data analyses are presented for each group stratified by treatment arm and compared to PBO. In the initial analysis, pts were categorized into 2 sub-groups defined as "Sustained" and "Fluctuating" depending on: CRP $<5 \mathrm{mg} / \mathrm{L} \mathrm{W} 4-16$ vs. CRP $\geq 5 \mathrm{mg} / \mathrm{L}$ at any point beyond W4 between weeks 4-16 respectively. In a second analysis, pts were categorized based on BASDAI Q5/6 improvement: "Sustained" if $\geq 2$-pt improvement W12-16 vs. "Fluctuating" if <2-pt improvement at any point beyond W12 between W12-16.

Results: Between W0 and W16, pts treated (tx) with IXEQ4W experienced greater reduction in SP-N than pts tx with ADA, in both CRP sustained and fluctuating groups (Fig 1a). Pts in the IXEQ4W and ADA arms showed different trajectories of pain improvement in the CRP fluctuating groups. For the pts with a fluctuating $C R P \geq 5 \mathrm{mg} / \mathrm{L}$, pts in IXEQ4W arm demonstrated a greater reduction in SP-N compared to pts in PBO arm $(p<.001)$ at W16, whereas pts in ADA arm did not experience a reduction in SP-N compared to PBO $(p=.416)$. For the pts with a sustained CRP $<5 \mathrm{mg} / \mathrm{L}$, IXEQ4W and ADA treatments both significantly demonstrated reduction in SP-N compared to PBO at W16 (IXEQ4W: $p=.002$; ADA: $p=.02$ ), with IXEQ4W treatment showing a greater level of reduction (Fig 1a). The pts randomized to ADA and re-randomized to IXEQ2W or Q4W (ADA/IXE) experienced further improvement in SP-N. This effect was sustained over the 52 -wk period (Fig 1b). The same pattern of improvement in SP-N was observed when controlling for the BASDAI Q5/6; the SP-N improvement was greater in pts with a sustained BASDAI Q5/6 compared to pts with a fluctuating BASDAI Q5/6, regardless of treatment (Table 1). In the fluctuating BASDAI Q5/6, for pts in ADA/ IXE arm, further reduction of both spinal pain and SP-N were observed (Table 1).

Figure 1: Change in Spinal Pain at Night (SP-N) over 52 weeks by CRP, in active treatment arms, showing IXE and ADA re-randomized to IXE (Q2W and Q4W combined: ADA/IXE)

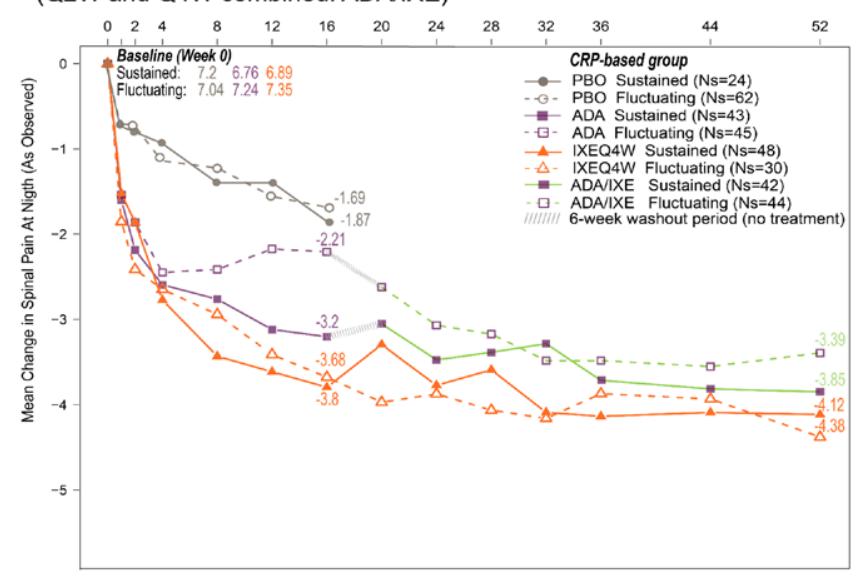

Conclusion: IXE reduced SP-N and spinal pain irrespective of CRP or morning stiffness. Additionally, pts treated with ADA re-randomized to IXE experienced a further reduction in SP-N and spinal pain. Collectively, these results support the additive benefits of IXE in reducing pain above measurable effects on inflammation.

Acknowledgements: The authors would like to thank Eglantine Julle-Daniere for writing and editorial contributions

Disclosure of Interests: Kurt de Vlam Speakers bureau: Eli Lilly, Novartis, Pfizer, Paid instructor for: Celgene, Amgen, Consultant of: Elil Lillyn Novartis, UCB, Galapagos, Sandoz, Pfizer, Grant/research support from: Celgene, Gaia Gallo Shareholder of: Eli Lilly, Employee of: Eli Lilly, Philip J Mease Speakers bureau: AbbVie, Amgen, Eli Lilly, Janssen, Novartis, Pfizer, UCB, Consultant of: AbbVie, Amgen, Boehringer Ingelheim, Bristol Myers Squibb, Eli Lilly, Galapagos, Gilead, GlaxoSmithKline, Janssen, Novartis, Pfizer, Sun, UCB, Grant/research support from: AbbVie, Amgen, Bristol Myers Squibb, Eli Lilly, Galapagos, Janssen, Novartis, Pfizer, Sun, UCB, Proton Rahman Speakers bureau: AbbVie, Amgen, BMS, Celgene, Eli Lilly, Janssen, Merck Novartis, Pfizer, UCB, Consultant of: AbbVie, Amgen, BMS, Celgene, Eli Lilly, Janssen, Merck, Novartis, Pfizer, UCB, Grant/research support from: Janssen, Novartis Venkatesh Krishnan Shareholder of: Eli Lilly, Employee of: Eli Lilly, David Sandoval Shareholder of: Eli Lilly, Employee of: Eli Lilly, Chen-Yen Lin Shareholder of: Eli Lilly, Employee of: Eli Lilly, Rebecca Bolce Shareholder of: Eli Lilly, Employee of: Eli Lilly, Philip G Conaghan Consultant of: personal fees from: AbbVie, AstraZeneca, BMS Eli Lilly, EMD Serono, Flexion Therapeutics, Galapagos, Gilead, Novartis, Pfizer DOI: 10.1136/annrheumdis-2021-eular.211

\section{POS0902 EFFICACY AND SAFETY OF INTRAVENOUS GOLIMUMAB IN ANKYLOSING SPONDYLITIS PATIENTS WITH EARLY VS LATE DISEASE THROUGH WEEK 52 OF GO-ALIVE STUDY}

A. Deodhar ${ }^{1}$, S. Kafka ${ }^{2}$, E. C. Hsia ${ }^{3,4}$, K. H. Lo ${ }^{5}$, L. Kim ${ }^{5}$, S. Xu' , J. D. Reveille ${ }^{6}$ ${ }^{1}$ Oregon Health \& Science University, Division of Arthritis and Rheumatic Diseases, Portland, United States of America; ${ }^{2}$ Janssen Scientific Affairs, LLC, Immunology, Horsham, United States of America; ' Janssen Research \& Development, LLC, Immunology, Spring House, United States of America; ${ }^{4}$ University of Pennsylvania, Rheumatology, Philadelphia, United States of America; ${ }^{5}$ Janssen Research \& Development, LLC, Biostatistics, Spring House, United States of America; ${ }^{6}$ University of Texas McGovern Medical School, Rheumatology And Clinical Immunogenetics, Houston, United States of America

Background: The GO-ALIVE study assessed efficacy and safety of intravenous golimumab (IV GLM) in patients (pts) with ankylosing spondylitis (AS). ${ }^{1,2}$

Objectives: In this post hoc analysis, we assessed IV GLM efficacy and safety in AS pts with early disease (ED) vs late disease (LD) based on pt-reported duration of inflammatory back pain (IBP).

Methods: In this Phase 3, double-blind, placebo (PBO)-controlled trial, pts with active AS were randomized (1:1) to receive IV GLM $2 \mathrm{mg} / \mathrm{kg}$ at Week (W) $0, \mathrm{~W} 4$ then Q8W or PBO at W0, W4, and W12 with crossover to IV GLM at W16, W20, then Q8W through 52. The primary endpoint was achievement of SpondyloArthritis International Society $20 \%$ improvement response (ASAS 20) at W16. In this post hoc analysis, 208 pts were grouped into quartiles based on self-reported duration of IBP symptoms. Efficacy and safety in 60 pts with ED ( $1^{\text {st }}$ quartile) were compared with 52 pts with LD ( $4^{\text {th }}$ quartile).

Results: For the overall study population, mean duration of IBP symptoms was $10.9 \mathrm{yr}$ and mean time since diagnosis was $5.5 \mathrm{yr}$. For ED pts, the mean duration of IBP symptoms ranged from $2.3 \mathrm{yr}$ (IV GLM) to $2.6 \mathrm{yr}$ (PBO), and for LD pts ranged from $23.5 \mathrm{yr}$ (IV GLM) to $24.4 \mathrm{yr}$ (PBO). At W16, ASAS 20 was achieved by $72 \%$ IV GLM vs $32 \%$ PBO pts with ED and by $67 \%$ IV GLM vs $21 \%$ PBO pts with LD. Pts with ED had numerically better response than those with LD in Bath Ankylosing Spondylitis Functional Index (BASFI), Bath Ankylosing Spondylitis Metrology Index (BASMI), and across more stringent endpoints, including ASAS 40, Bath Ankylosing Spondylitis Disease Activity Index 50\% improvemen

Table 1. Change in Pain Outcome at baseline, week 16 and week 52 by Inflammation Status as assessed by BASDAl or CRP levels for patients receiving placebo (PBO), adalimumab (ADA), and ixekizumab every 4 weeks (IXE Q4W)

Change from baseline

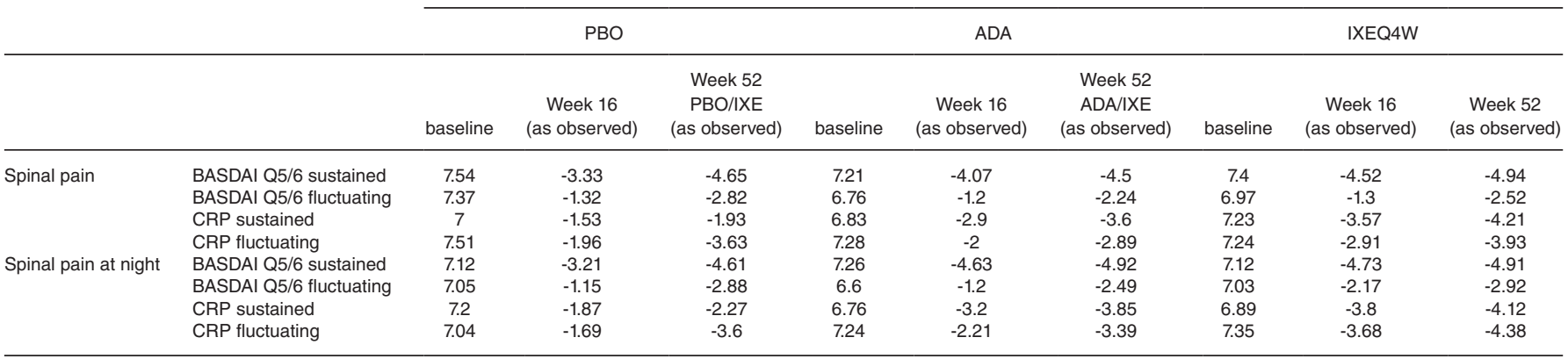

